\title{
Profit Maximization of Yield from Different Sizes of OFR
}

\author{
Mithlesh Kumar ${ }^{1 *}$, Sanjeeb Paul ${ }^{1}$, Sudhindra N. Panda ${ }^{1}$ and B. Panigrahi \\ ${ }^{1}$ Agricultural and Food Engineering Department, Indian Institute of Technology, \\ Kharagpur-721 302, West Bengal, India \\ ${ }^{2}$ Department of Soil and Water Conservation Engineering, College of Agricultural \\ Engineering and Technology, Orissa University of Agriculture and Technology, \\ Bhubaneswar-751003, Odisha, India \\ *Corresponding author
}

\section{A B S T R A C T}

A Dynamic Programing (DP) model is developed to allocate optimum supplemental irrigation to crop for receives maximum net annual return from the cropped area under land and water availability constraints in the OFR based rainfed agricultural system. The model integrates the dynamics associated with the water released by supplemental

\section{Keywords}

Dynamic programing, Supplemental irrigation,

On-farm reservoir, Soil

moisture dynamics, Yield response

Article Info

Accepted:

10 February 2018

Available Online:

10 March 2018 irrigation from the OFR to the actual water utilized by the crops at farm level. It also takes into account the non-linear relationship of root growth, soil moisture dynamics for multiple crops and yield response to water deficit at various growth stages of the crops. The DP model is simulated for $5 \%$ to $12 \%$ field area and economic benefits from the crops takes into accounted for optimum size of OFR. For $10 \%$ soil water depletion for rice (from saturation) and mustard (from field capacity) crops, the optimum size of OFR varied from $5.35 \%$ to $9.85 \%$. Similarly, for $15 \%$ soil water depletion it varied from $5.05 \%$ to $9.35 \%$.Relative yield for $10 \%$ soil water depletion for rice (from saturation) and mustard (from field capacity) crops varied from 0.65 to 0.88 and 0.85 to 0.94 . Similarly, for $15 \%$ soil water depletion it varied from 0.70 to 0.90 for rice and 0.88 to 0.96 for mustard crop. If only rice crop is grown, the optimum size of OFR for $10 \%$ soil water depletion varied from $0.00 \%$ to $6.90 \%$, whereas for $15 \%$ soil water depletion it varied from $0.00 \%$ to $6.70 \%$. Similarly, relative yield for $10 \%$ and $15 \%$ soil water depletion varied from 0.70 to 0.90 and 0.74 to 0.93 , respectively. In low water availability condition, the model performance is very good because it allocate supplemental irrigation at the time when crop has high yield response factor.

\section{Introduction}

Rice (Oryza sativa), a major crop in rainy season, is the staple food of the people in eastern India and so, it is grown extensively in all types of land topography. Out of 44 million ha of total rice area in the country, the upland rice occupies 7 million ha ofwhich $75 \%$ is from eastern India only (Kar et al., 2004). The average yield of rice from this area is very low because of uneven distribution rainfall in crop growing season. Due to this scope of growing a second crop after withdrawal of monsoon is also very much limited due to quick depletion 
of soil moisture. Verma and Sarma (1990) developed a procedure to design water storage and recycling tank and compute the benefitcost ratio for a region in northern Punjab. It was observed that the total cost of tank per unit of capacity decreased with increasing tank capacity. Tanks designed on the basis of seasonal runoff and used for pre-sowing irrigation of wheat, were the most beneficial with a benefit-cost ratio ranging from 1.60 to 4.56 for catchment areas varying from 1 to 100 ha. Panigrahi and Panda (2003) reported that an OFR having a depth of $2.0 \mathrm{~m}$ covering $12 \%$ of the $800 \mathrm{~m}^{2}$ farm area with a volume of $61 \mathrm{~m}^{3}$ was optimum for applying supplemental irrigation to rice-mustard cropping system. The yields of rice grain and mustard seed were increased by 39 and 15\%, respectively, over rainfed condition due to application of 84 and $45 \mathrm{~mm}$ of supplemental irrigation to respective crops. Islam et al., (1998) reported 20\% increase in yield of irrigated crop over rainfed (non-irrigated) farm in low rainfall areas of Bangladesh with a benefit-cost-ratio of 1.5.

Arnold and Stockle (1991) developed a simulation model to determine the optimum size of pond and to plan different irrigation strategies for supplemental irrigation systems. A comprehensive basin scale soil and waterresource model is modified to simulate crop yield, supplemental irrigation, and economics. The model is capable of determining the effects of various management strategies on crop production and sediment yield. Mahendrarajah et al., (1992) analyzed the optimization of monsoonal water storage tank for supplemental irrigation under double rice cropping in Sri Lanka. Mujumdar and Ramesh (1998) developed a short-term yearly reservoir operation model for irrigation of multiple crops. Sharma (2002) developed computer software to design water harvesting structure for different agro-climatic regions in India. After economic analysis he found that for Dasuya (Orissa), the benefit-cost ratio were greater than one, up to $40 \%$ probability. For Indore (M.P.), the benefit-cost ratio were greater than one, up to $60 \%$ probability level and beyond that these were less than one, but for the study site at Kansas (Punjab), the benefit-cost ratio has been just equal to one up to 50\% probability. Singh and Panda (2012) developed a linear programming model for the optimal land and water resources allocation in order to maximize net annual returns from an irrigated area located in the Haryana State of India. The water production functions were incorporated in the model to estimate the crop yield under different qualities of irrigation water. The net annual return from the study area has increased by about $26 \%$. The objective of present study is to maximize yield from different sizes of the OFR under single and dual cropping situations.

\section{Materials and Methods}

\section{Study area}

The site selected for the present study is the experimental farm of the Agricultural and Food Engineering Department of Indian Institute of Technology, Kharagpur in West Bengal state, India. It is located at Latitude $22^{\circ} 19^{\prime} \mathrm{N}$, Longitude $87^{\circ} 19^{\prime} \mathrm{E}$ and altitude $48 \mathrm{~m}$ above the mean sea level. The total field area is select as $800 \mathrm{~m}^{2}$ (including OFR area and crop area). Mean annual rainfall of the study area is about $1500 \mathrm{~mm}$, of which about $80 \%$ is received during monsoon season in between June and September. Maximum and minimum relative humidity (RH) during kharif and rabi season crops were nearly $98.2 \%$ and $51.9 \%$, respectively. The average wind velocity was $2.17 \mathrm{~km} / \mathrm{h}$ and $1.0 \mathrm{~km} / \mathrm{h}$, respectively. Water holding capacity of the sandy loam soil in the experimental site is very low. It dries up quickly after cessation of rainfall. Field capacity, wilting point, saturation soil moisture, and pore connectivity index of the soil are $20 \%, 9 \%, 36 \%$, and 0.25 , respectively. 


\section{Field water balance module}

Daily field water balance simulation modeling was done to estimate the supplemental irrigation (SI) requirement of kharif crops and surface runoff (SR) generated from the cropped field.

For simplicity in modeling, rice plots were considered as leveled fields. Soil, crop and daily weather data were used as input to run the water balance model.

The inflow components of the model are direct rainfall $(\mathrm{R})$ and $\mathrm{SI}$ from the lined/unlined OFR and outflow components are the actual crop evapotranspiration (AET), seepage \& percolation (SP) and SR diverted to the OFR.

Considering the effective root zone as a single layer, the general water balance model under unsaturated conditions can be expressed as (Panigrahi and Panda, 2003; Panigrahi et al., 2005):

$\mathrm{SMC}_{\mathrm{i}}=\mathrm{SMC}_{\mathrm{i}-1}+\mathrm{R}_{\mathrm{i}}+\mathrm{SI}_{\mathrm{i}}-\mathrm{AET}_{\mathrm{i}}-\mathrm{SP}_{\mathrm{i}}-\mathrm{SR}_{\mathrm{i}}$

Where, SMC = soil water content in the crop root zone $(\mathrm{mm}) ; \mathrm{R}=$ rainfall $(\mathrm{mm}) ; \mathrm{SR}=$ surface runoff $(\mathrm{mm}) ;$ SI $=$ supplemental irrigation $(\mathrm{mm}) ; \quad$ AET $=$ actual evapotranspiration $(\mathrm{mm})$; $\mathrm{SP}=$ seepage and percolation losses $(\mathrm{mm})$ and $\mathrm{i}=$ time index taken as days after sowing.

If $\mathrm{SMC}$ is more than saturation moisture content (SAT), then ponding will occur in the field.

Under the ponding phase, the water balance in rice field can be expressed as (Panigrahi et al., 2001):

$D_{i}=D_{i-1}+R_{i}+S I_{i}-A E T_{i}-S P_{i}-S R_{i}$
Where, $D$ is the ponding depth in rice field, $\mathrm{mm}$.

\section{Supplemental irrigation}

In the present study, 10 and $15 \%$ depletion from saturation moisture content $(S A T)$ and field capacity $(F C)$ for rice and non-rice crop, respectively, was considered for supplemental irrigation $(S I)$ from the OFR. Irrigation was allowed to be continued till $S A T$ for rice and $F C$ for non-rice crop was reached.

\section{SI for rice crop}

$$
S I_{i}=0, \text { if } S M C_{i}>X \% \text { of SAT; } \text { ElSeSI }_{i}=\left(S A T-S M C_{i}\right)
$$

\section{SI for non-rice crop}

$S I_{i}=0$, if $S M C_{i}>Y \%$ of $F C_{;}$ElseSI $I_{i}=\left(F C-S M C_{i}\right)$

Where, $X=$ soil moisture depletion from $S A T$, $\% ; Y=$ soil moisture depletion from $F C, \%$;

\section{Water balance module of the OFR}

The capacity of any OFR must be sufficient to store all the excess rainfall generated from the cropped fields. In the present study, the top width, height, free board and berm width of the embankment were fixed at 30, 30, 15 and $30 \mathrm{~cm}$ respectively, the side slope was taken as 1:1 and the depth of the OFR was taken as $2.4 \mathrm{~m}$.

The volume of water stored in an OFR on any day can be found out by the information on previous day's storage and various inflow and outflow components of the OFR. The inflow components include the surface runoff coming from the cropped field and the direct rainfall, whereas evaporation, supplemental irrigation, seepage and percolation are the outflow components of the OFR (Panigrahi et al., 2007). 
$F V_{i}=F V_{i-1}+V R_{i}+V Q_{i}-V E_{i}-V S I_{i}-V S P_{i}$

where, $F V=$ final volume of water in the OFR, $\mathrm{m}^{3} ; V R=$ volume of direct rainfall in the $\mathrm{OFR}^{\left(=R_{i} \times A_{\text {OFR }}\right)}, \mathrm{m}^{3} ; V Q=$ volume of surface runoff coming from the field to the $\mathrm{OFR}^{\left(=S R_{i} \times A_{\text {crop }}\right)}, \mathrm{m}^{3} ; V E=$ volume of water lost as evaporation from the OFR, $\mathrm{m}^{3}$; $V S I=$ volume of water used as supplemental irrigation in the cropped field $\left(=\frac{S I_{\mathrm{i}} \times A_{\text {crop }}}{\eta}\right)$, $\mathrm{m}^{3} ; V S P=$ volume of water lost as seepage and percolation from the OFR storage, $\mathrm{m}^{3} ;^{A_{\text {OFR }}}=$ surface area of the OFR, $\mathrm{m}^{2} ;{ }^{A_{\text {crop }}}=$ area of crop field equal to $\left(A_{F a r m}-A_{O F R}\right), \mathrm{m}^{2}$, in which ${ }^{A_{\text {Farm }}}$ is the area of the farm, $\mathrm{m}^{2} ;{ }^{\eta}$ is the irrigation system efficiency, fraction; and $i$ $=$ time index, considered as one day.

\section{Economic analysis}

In any economic analysis, all cash flows must be evaluated at some reference time. A present worth analysis is an economics tool. It helps converting all the cash flows (inflows and outflows) over the life span of the project, using appropriate factors to account for interest and inflation, into an equivalent present value at the beginning. It is also a widely adopted method (Palmer et al., 1981; Verma and Sharma, 1990; Islam et al., 1998) to study the economics of water harvesting and recycling reservoirs.

An economic analysis is often associated with preparing a balance sheet of fixed and variable costs in a system against the amount of return.

While the fixed cost consists of the initial one time investment in the system, the variable cost includes the parameters those demand investment every year or at some recurrence interval during the life span of the project.

\section{Irrigation cost}

Supplemental irrigations to crops during the rainy season are provided with hiring irrigation pumps and conveyance pipes. The operation is accomplished with hiring pump set and sprinkler unit for crops during winter season. Hiring charges of the pump set with conveyance pipes or sprinkler unit in the locality in Kharagpur, West Bengal have been taken into account to calculate the irrigation cost on an annual basis for the farm. One kerosene run $3 \mathrm{hp}$ centrifugal pump is hired at the rate of Rs. $120 \mathrm{hr}^{-1}$ for the purpose.

\section{Production cost of crops}

The production cost of crops includes the cost of all the agricultural inputs, including labor wage, except irrigation cost in the present study. The production cost of all the crops, excluding irrigation cost, is shown in Table 1.

\section{Present worth analysis}

Cash flow in the OFR irrigation system is divided into (a) cash inflow; and (b) cash outflow. The cash inflow includes annual returns from irrigation and cash outflow includes initial investment and variable costs in the system. Annual cash inflows and outflows throughout the life period of the system are converted to their present worth using interest and inflation rate prevailing at the beginning of the system.

\section{Cash outflow}

$P W_{c o}=I_{n v}+P W_{v}(6)$

Where, $\mathrm{PW}_{\mathrm{co}}=$ present worth of cash outflow (Rs); $\mathrm{I}_{\mathrm{nv}}=$ initial investment $(\mathrm{Rs})$; and $\mathrm{PW}_{\mathrm{v}}=$ present worth of total variable cost (Rs).

Since, the initial investment is made at the beginning of the project so, the present worth 
of initial investment is equal to the initial investment itself. Annual variable costs likely to be incurred each year are converted to their present worth values and are assumed flowing at the beginning of the project.

$$
\begin{aligned}
& P W_{a v}=\sum_{t=1}^{n} A_{n r}(1+f)^{t-1}(1+r)^{-t} \\
& A_{n r}=A_{\text {irrigated }}-A_{\text {rainf } e d}
\end{aligned}
$$

Where, $\mathrm{A}_{\mathrm{nr}}=$ net annual return from the OFR system (Rs); $\mathrm{PW}_{\mathrm{av}}=$ present worth of net return from the system $(\mathrm{Rs}) ; \mathrm{A}_{\text {irrigated }}=$ return from the OFR system with the provision of SI $(\mathrm{Rs})$; and $\mathrm{A}_{\text {rainfed }}=$ return from rainfed system without SI (Rs).

\section{Net profit due to supplemental irrigation}

Net profit, an economic index, is used to test whether the cost involved in the intervention of the OFR is acceptable or not.

In the present study, the net profit due to supplemental irrigation (SI) from the OFR has been computed by taking the differential return between irrigated and rainfed conditions. A negative net profit suggests rejection of the OFR irrigation system.

$$
N P=P W_{n r}-P W_{c o}(8)
$$

Where, NP = net profit due to SI from the OFR over rainfed situation, Rs.

\section{Results and Discussion}

The developed on-farm reservoir (OFR) operation model for irrigating crops (decision variable) is solved using dynamic programming technique by utilization the harvested water in the OFR (state variable) to maximize the relative crop yield (objective function). Finally, the optimum sizing of the
OFR is determined by considering maximum return from the field. The model considers rice in kharif season and mustard in rabi season. However, if there is a competition among the crops for limited water available in the OFR, the allocation of irrigation water to crops will depend on crop growth stages, sensitivity to water stress, and its effect on final yield. In the study area, water deficiency exists mainly in rabi season, since the kharif crop receives a good amount of rainfall in monsoon season.

\section{Crop data}

The major crops grown during kharif and rabi seasons are rice and mustard, respectively. The crop parameters are presented in Table 2.

\section{Determination of OFR by net profit analysis}

Economic analysis of OFR sizes from 5\% to $12 \%$ was carried out for 30 years from 19852014 and their results (2014) are presented in Table 3.

It was found that the initial investment, present worth of cash outflows and net return are increasing with the increase in the size of the OFR. The initial investment that includes cost of earthwork and lining is Rs.11809.

When the size of the OFR increases from $5 \%$ to $12 \%$ of the field area, the cost gradually increases to Rs.28208. Similarly, the present worth of cash outflows increased from Rs.21683 to Rs.45943 when the size of lined OFR increased from 5 to $12 \%$ of the field.

Pertaining to present worth of net return from the farm with provision of SI, it was observed to be increasing from Rs.31010 to Rs.63341as the OFR size increases from 5 to $12 \%$. However, it may be noticed that the net profit is highest when the OFR size is $9 \%$ of the field area (Rs. 19739). 
Table.1 Production cost of crops, their minimum support prices (MSP) and local market prices of by-products

\begin{tabular}{|c|c|c|c|}
\hline Crop & $\begin{array}{c}\text { Cost of production } \\
\text { (Rs ha }^{-1} \text { ) }\end{array}$ & $\begin{array}{c}\text { MSP of grain/seed } \\
\text { (Rs/100kg) }\end{array}$ & $\begin{array}{c}\text { Local market price of } \\
\text { by-products (Rs/100kg) }\end{array}$ \\
\hline Rice & 9540 & 745 & 40 \\
\hline Mustard & 4160 & 1735 & 20 \\
\hline
\end{tabular}

Source: Dept. of Agriculture and Economics, minimum support price for 2003-14 season, Govt. of India

Table.2 Crop parameters for rice and mustard

\begin{tabular}{|c|}
\hline Crop parameters \\
\hline Standard week of sowing \\
\hline Crop duration (day) \\
\hline Length of crop growth stages (day) \\
\hline Crop coefficient at different stages \\
$\left(\mathbf{k}_{\mathbf{c}}\right)$ \\
\hline Yield response factors at \\
differentstages $\left(\mathbf{k}_{\mathbf{y}}\right)$
\end{tabular}

\begin{tabular}{|c|c|}
\hline Rice & Mustard \\
\hline $26^{\text {th }}$ & $43^{\text {rd }}$ \\
\hline 99 & 70 \\
\hline $25,20,30,24$ & $9,16,30,15$ \\
\hline $1.0,1.15,1.11,1.0$ & $0.34,0.61,0.88,0.82$ \\
\hline $1.1,1.1,2.4,0.33$ & $0.3,0.6,0.6,0.3$ \\
\hline 45 & 100 \\
\hline 17.4 & 8.1 \\
\hline
\end{tabular}

Table.3 Economics of various sizes of lined OFR irrigation system for $800 \mathrm{~m}^{2}$ upland farm area in 2014

\begin{tabular}{|c|c|c|c|c|c|}
\hline $\begin{array}{l}\text { OFR } \\
\text { size } \\
(\%)\end{array}$ & $\begin{array}{c}\text { Initial } \\
\text { investment } \\
(\mathrm{Rs})\end{array}$ & $\begin{array}{c}\text { Present worth of } \\
\text { total variable cost } \\
\text { (Rs) }\end{array}$ & $\begin{array}{l}\text { Present worth } \\
\text { cash outflow } \\
\text { (Rs) }\end{array}$ & $\begin{array}{l}\text { Present worth } \\
\text { of net return } \\
\text { due to SI (Rs) }\end{array}$ & $\begin{array}{c}\text { Net } \\
\text { profit } \\
\text { (Rs) }\end{array}$ \\
\hline 5 & 11809 & 9874 & 21683 & 31010 & 9327 \\
\hline 5.5 & 12899 & 10438 & 23337 & 33613 & 10276 \\
\hline 6 & 14000 & 10936 & 24936 & 36210 & 11274 \\
\hline 6.5 & 15113 & 11548 & 26661 & 37879 & 11218 \\
\hline 7 & 16234 & 12140 & 28374 & 42406 & 14032 \\
\hline 7.5 & 17365 & 12727 & 30092 & 44724 & 14632 \\
\hline 8 & 18703 & 13268 & 31971 & 47483 & 15512 \\
\hline 8.5 & 19847 & 13880 & 33727 & 51969 & 18242 \\
\hline 9 & 20998 & 14420 & 35418 & 55157 & 19739 \\
\hline 9.5 & 22154 & 14933 & 37087 & 56699 & 19612 \\
\hline 10 & 23516 & 15462 & 38978 & 58582 & 19604 \\
\hline 10.5 & 24682 & 16038 & 40720 & 60113 & 19393 \\
\hline 11 & 25853 & 16587 & 42440 & 61603 & 19163 \\
\hline 11.5 & 27029 & 17137 & 44166 & 62575 & 18409 \\
\hline 12 & 28208 & 17735 & 45943 & 63341 & 17398 \\
\hline
\end{tabular}


Table.4 The optimal size of OFR in different probability of exceedance level, different cropping scenario and different soil water depletion factor

\begin{tabular}{|c|c|c|c|c|}
\hline \multirow{2}{*}{$\begin{array}{c}\text { Probability of } \\
\text { exceedance (\%) }\end{array}$} & \multicolumn{4}{|c|}{ OFR size (\%) } \\
\hline & $\begin{array}{c}\text { Rice -Mustard } \\
\mathbf{( 1 0 \% )}\end{array}$ & $\begin{array}{c}\text { Rice -Mustard } \\
\mathbf{( 1 5 \% )}\end{array}$ & Rice (10\%) & Rice (15\%) \\
\hline $\mathbf{5}$ & 9.68 & 9.30 & 6.57 & 6.21 \\
\hline $\mathbf{1 0}$ & 9.40 & 9.02 & 6.39 & 6.05 \\
\hline $\mathbf{1 5}$ & 9.23 & 8.84 & 6.27 & 5.95 \\
\hline $\mathbf{2 0}$ & 9.09 & 8.69 & 6.18 & 5.86 \\
\hline $\mathbf{2 5}$ & 8.97 & 8.57 & 6.10 & 5.79 \\
\hline $\mathbf{3 0}$ & 8.86 & 8.46 & 6.03 & 5.72 \\
\hline $\mathbf{3 5}$ & 8.77 & 8.36 & 5.96 & 5.65 \\
\hline $\mathbf{4 0}$ & 8.68 & 8.27 & 5.89 & 5.59 \\
\hline $\mathbf{4 5}$ & 8.59 & 8.09 & 5.83 & 5.52 \\
\hline $\mathbf{5 0}$ & 8.51 & 8.13 & 5.76 & 5.45 \\
\hline
\end{tabular}

Fig.1 Variations in the OFR size, relative yield of rice (10\% soil moisture depletion from saturation), and mustard (10\% soil moisture depletion from field capacity) to maximize net annual return during 1985 - 2014

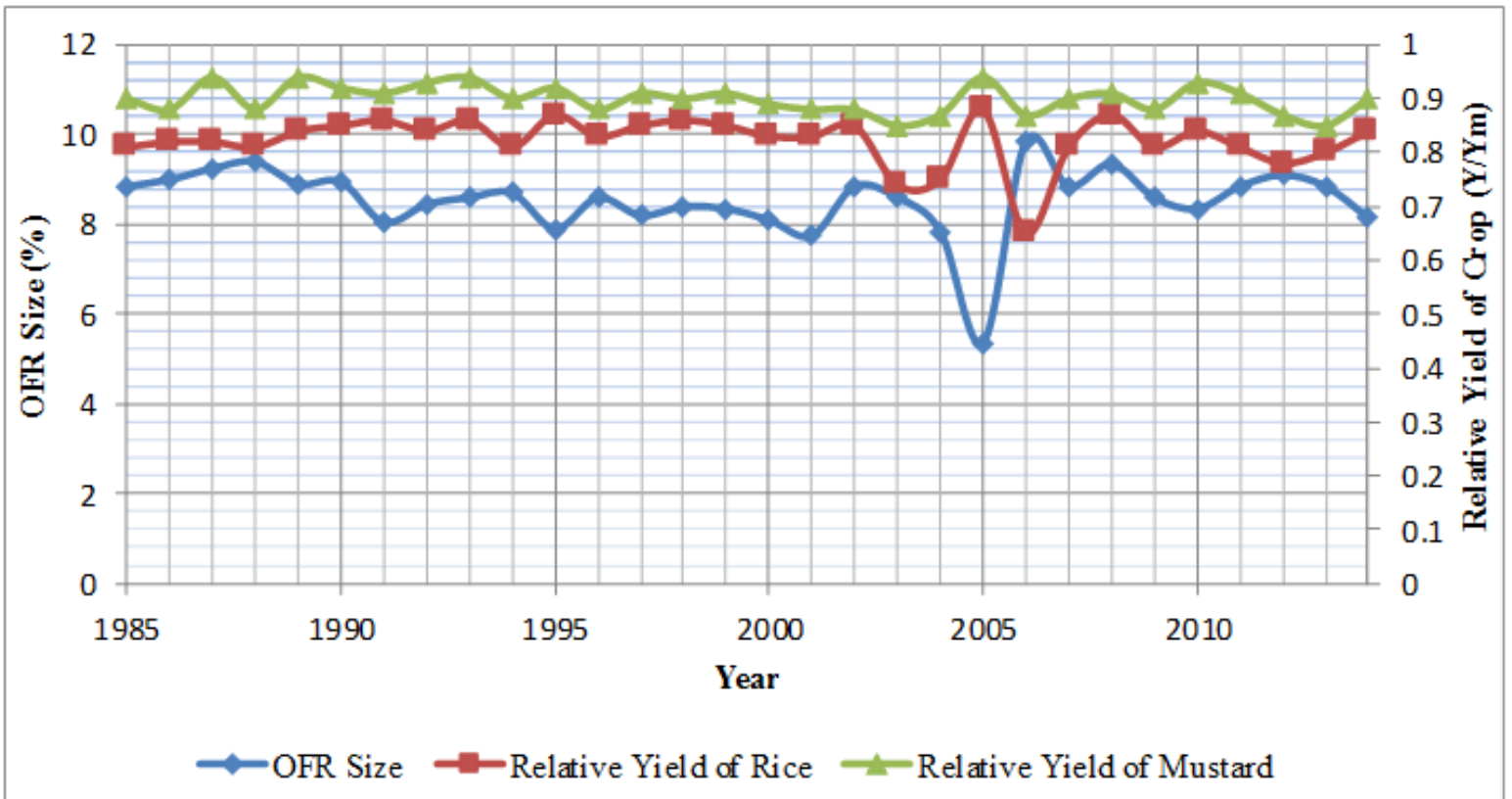


Fig.2 Variations in the OFR size, relative yield of rice (15\% soil moisture depletion from saturation), and mustard (15\% soil moisture depletion from field capacity) to maximize net annual return during $1985-2014$

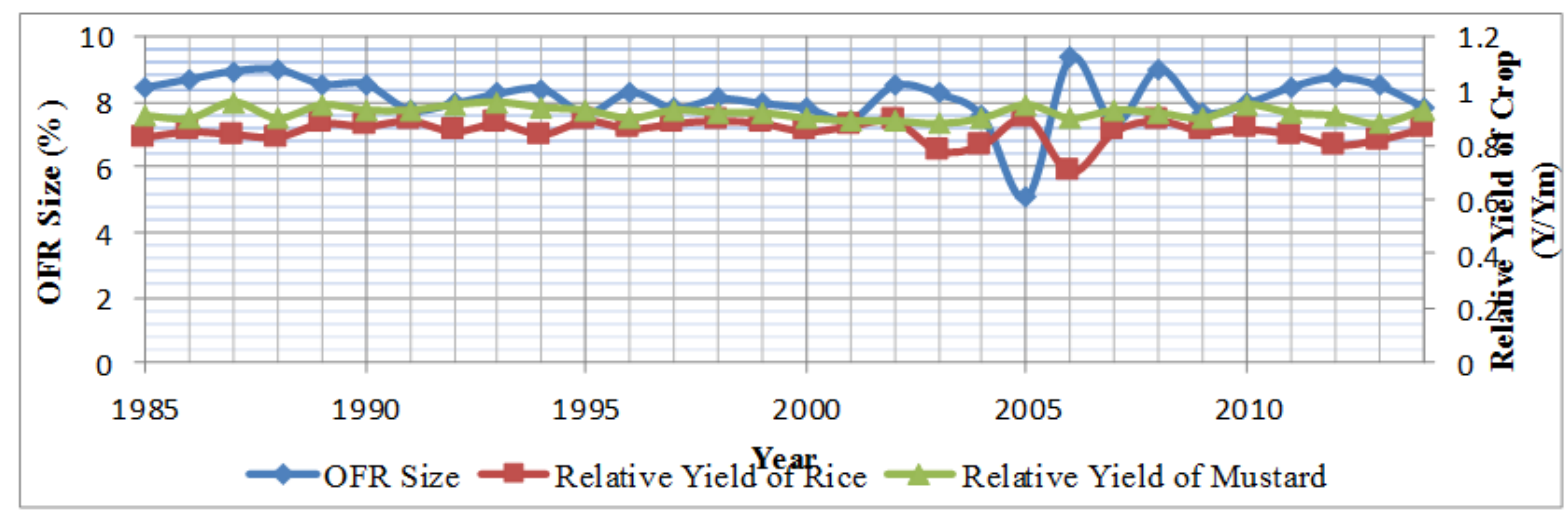

Fig.3 Variations in the OFR size and relative yield of rice at 10\% soil moisture depletion from saturation to maximize net seasonal return during 1985 - 2014

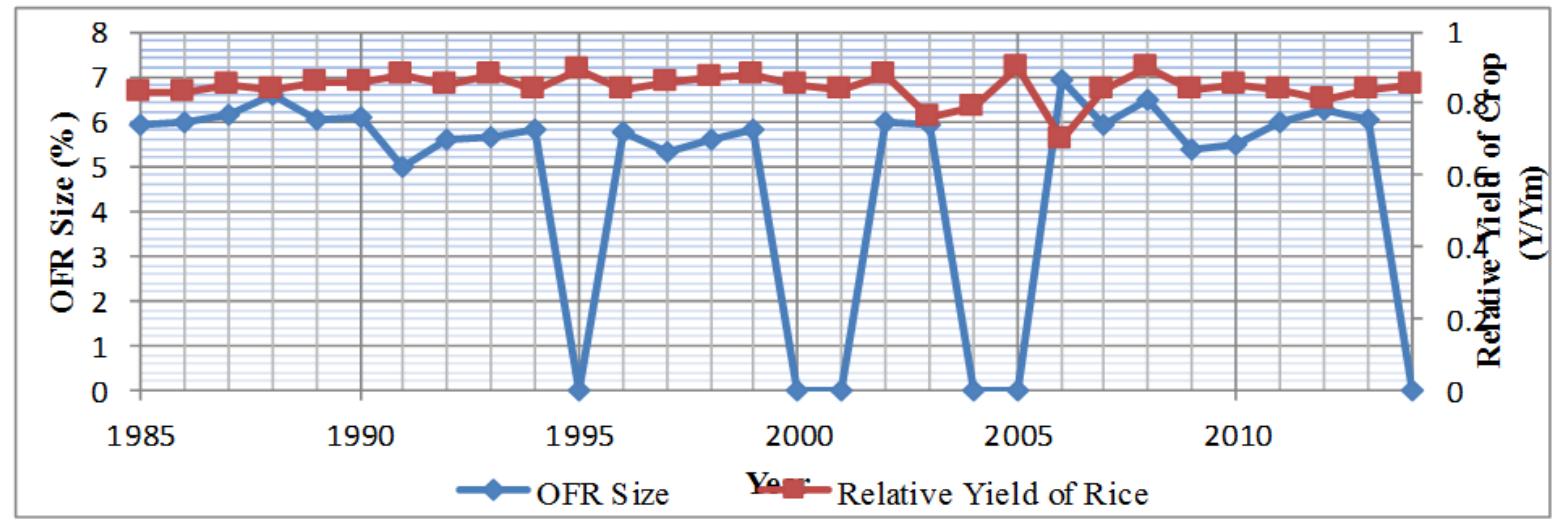

Fig.4 Variations in the OFR size and relative yield of rice at 15\% soil moisture depletion from saturation to maximize net seasonal return during $1985-2014$

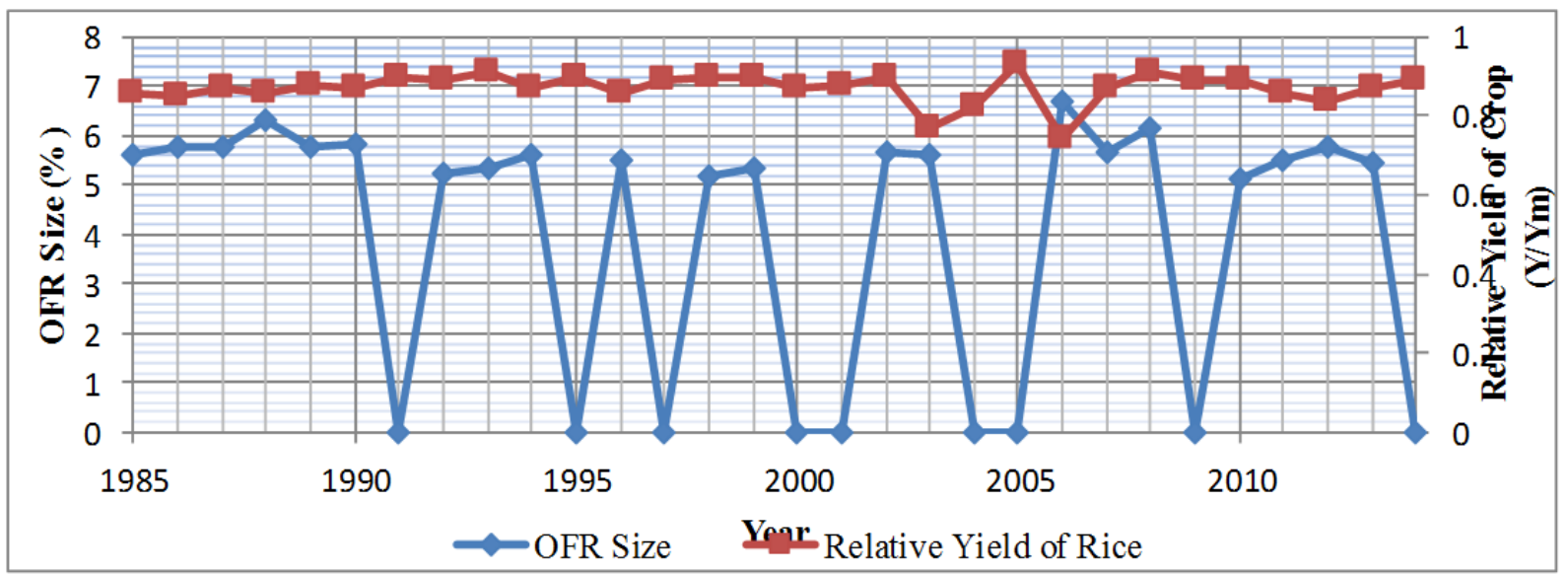


Determination of OFR size under different soil water depletion factor for rice - mustard in different years

The model was run to calculate OFR size under rice-mustard cropping sequence in $800 \mathrm{~m}^{2}$ field areas and OFR depth was maintained as $2.5 \mathrm{~m}$. In case of rice crop, $10 \%$ and $15 \%$ soil water depletion from saturation was considered.

Whereas for mustard crop, $10 \%$ and $15 \%$ soil water depletion from field capacity was considered (Figure 1 and 2). Represents the variation of optimum size of OFR area (\%) and relative yield of rice and mustard crops in different years.

In case of $10 \%$ soil water depletion for rice and mustard crops, optimum OFR size varies from $5.35 \%$ to $9.85 \%$, relative yield of rice varies from 0.65 to 0.88 and relative yield of mustard varies from 0.85 to 0.94 .

In case of $15 \%$ soil water depletion for rice and mustard crops, optimum OFR size varies from $5.05 \%$ to $9.35 \%$, relative yield of rice varies from 0.70 to 0.90 and relative yield of mustard varies from 0.88 to 0.96 . The OFR size was higher and relative yield of rice and mustard was low in case of $10 \%$ depletion than in $15 \%$ depletion.

\section{Determination of OFR size under different soil water depletion factor for rice}

The model was run to calculate OFR size under rice crop $10 \%$ and $15 \%$ soil water depletion from saturation was considered. Figure 3 and 4 represent the variation of optimum size OFR area (\%) and relative yield of rice crop in different years. In case of $10 \%$ soil water depletion from saturation for rice crop, optimum OFR size varies from $0.0 \%$ to $6.90 \%$, relative yield of rice varies from 0.70 to 0.90 . In case of $15 \%$ soil water depletion from saturation, optimum OFR size varies from $0.0 \%$ to $6.7 \%$ and relative yield varies from 0.74 to 0.93 . The OFR size was higher and relative yield of rice crop was low in case of $10 \%$ depletion than in $15 \%$ depletion.

Determination of OFR size in different probability of exceedance level in different cropping scenario

Optimum sizes of OFR (30 years) were fitted to lognormal probability distribution function (FLOOD software developed by Goutam Kumar Dey and Prof. S. N. Panda.

Determined OFR size at different probability of exceedance (PE) levels from 5\% to $50 \%$ is illustrated in Table 4. It was observed that the OFR size is maximum when PE value is less and OFR size is gradually decreasing with the increase in value of PE in all cropping scenario.

For $10 \%$ soil water depletion for rice (from saturation) and mustard (from field capacity) crops, the optimum size of OFR varied from $5.35 \%$ to $9.85 \%$. Similarly, for $15 \%$ soil water depletion it varied from $5.05 \%$ to $9.35 \%$.Relative yield for $10 \%$ soil water depletion for rice (from saturation) and mustard (from field capacity) crops varied from 0.65 to 0.88 and 0.85 to 0.94 .

Similarly, for $15 \%$ soil water depletion it varied from 0.70 to 0.90 for rice and 0.88 to 0.96 for mustard crop. If only rice crop is grown, the optimum size of OFR for $10 \%$ soil water depletion varied from $0.00 \%$ to $6.90 \%$, whereas for $15 \%$ soil water depletion it varied from $0.00 \%$ to $6.70 \%$.

Similarly, relative yield for $10 \%$ and $15 \%$ soil water depletion varied from 0.70 to 0.90 and 0.74 to 0.93 , respectively. For $5 \%$ to $50 \%$ probability of exceedance level, the optimum size of OFR for $10 \%$ soil water depletion for rice (from saturation) and mustard (from field capacity) crops varied from $9.68 \%$ to $8.51 \%$. Similarly, for $15 \%$ soil water depletion it varied from $9.30 \%$ to $8.13 \%$. If only rice crop is grown and $5 \%$ to $50 \%$ probability of exceedance level is considered, the optimum size of OFR for $10 \%$ and $15 \%$ soil water depletion level varied from $6.57 \%$ to $5.76 \%$ and $6.21 \%$ to $5.45 \%$. In 
low water availability condition, the model performance is very good because it allocate supplemental irrigation at the time when crop has high yield response factor. If a year from a particular size of OFR the return of the crop is less than the return came from no OFR condition then it show no OFR required at that year.

\section{References}

Arnold, J.G., and Stockel, C.O. (1991). Simulation of supplemental irrigation from on-farm ponds. Journal of Irrigation and Drainage Engineering, ASCE, 117(3): 408-424.

Islam, M.T., Saleh, A.F.M., and Bhuiyan, S.I. (1998). Agro-hydrologic and economic analyses of onfarm reservoirs for drought alleviation in rainfed rice lands of northwest Bangladesh. Rural and Environmental Engineering, 35: 15-26.

Kar, G., Singh, R., and Verma, H.N. (2004). Alternate cropping strategies for assured and efficient in upland rainfed rice areas of eastern India based on rainfall analysis. Agricultural Water Management, 67(1): 47-62.

Mahendrarajah, S., War, P.G., and Jakeman, A.J.J. (1992). Optimal extraction of small-scale surface storage in Asia. Water Resources Research, ASCE, 28(5): 12071220.

Mujumdar, P.P., and Ramesh, T.S.V. (1998). A short-term reservoir operation model for multicrop irrigation. Hydrological Sciences Journal, 43(3): 479-494.

Palmer, W.L., Barfield, B.J., and Haan, C.T. (1981). Sizing farm reservoirs for supplemental irrigation of corn. Part I: reservoir size-yield relationships. Transactions of the ASAE, 11: 272-276.

Panigrahi, B., and Panda, S.N. (2003). Optimal sizing of on-farm reservoirs for supplemental irrigation. Journal of Irrigation and Drainage Engineering, ASCE, 129(2): 117-128.

Panigrahi, B., Panda, S.N., and Agrawal, A. (2005). Water balance simulation and economic analysis for optimal size of onfarm reservoir. Water Resources Management, 19(3): 233-250.

Panigrahi, B., Panda, S.N., and Mal, B.C. (2007). Rainwater conservation and recycling by optimal size on-farm reservoir. Journal of Recourses, Conservation and Recycling, 50: 459 474.

Panigrahi, B., Panda, S.N., and Mull, R. (2001). Simulation of water harvesting potential in rainfed rice lands using water balance model. Agriculture System, 69(3): 165182.

Sharma, K.K. (2002). Designing water harvesting ponds for different rainfall regions and water shed areas. Ph.D. Thesis, Division of Agricultural Engineering, IARI, New Delhi.

Singh, A., and Panda, S.N. (2012). Development and application of an optimization model for the maximization of net agricultural return. Agricultural Water Management, 115: 267-275.

Verma, H.N., and Sharma, P.B. (1990). Design of storage tanks for water harvesting in rainfed areas. Agricultural Water Management, 18: 195-207.

\section{How to cite this article:}

Mithlesh Kumar, Sanjeeb Paul, Sudhindra N. Panda and Panigrahi, B. 2018. Profit Maximization of Yield from Different Sizes of OFR. Int.J.Curr.Microbiol.App.Sci. 7(03): 1206-1215. doi: https://doi.org/10.20546/ijcmas.2018.703.142 